\title{
Uma comemoração para o futuro: aceleração e progresso no cinquentenário de Chapecó (1967)
}

Gustavo Henrique de Siqueira*

\author{
Palavras-chave: \\ Chapecó \\ Cinquentenário \\ Progresso
}

Keywords:

Chapecó

Fiftieth Anniversary

Progress

\begin{abstract}
Resumo: Este artigo discute a comemoração do cinquentenário do município de Chapecó em 1967 pelas páginas do jornal Folha d'Oeste como um evento cujo regime de historicidade era voltado para o horizonte de expectativas. A partir dos referenciais a respeito da aceleração da História (Koselleck), observamos que a cobertura da festividade pelo periódico tratava muito menos dos cinquenta anos passados que levaram o município até aquela ocasião (priorizando, nesse passado, a trajetória do empresariado local e ignorando a existência de povos indígenas e trabalhadores ditos "caboclos") e muito mais do futuro, utilizando da cobertura do evento para divulgar e propagandear as terras e a economia local para atrair investimentos que trouxessem desenvolvimento para a região. Observamos que na leitura do periódico o passado deveria ser superado em diversos aspectos (principalmente em relação à violência praticada em um linchamento) e o futuro, dilatado, deveria ser evocado constantemente em nome do progresso.
\end{abstract}

\begin{abstract}
This article discusses the commemoration of the fiftieth anniversary of the Chapecó city in 1967 by the pages of the newspaper Folha d'Oeste as an event whose historicity regime was focused on the horizon of expectations. From the references to the acceleration of history (Koselleck), we observed that the coverage of the festival by the periodical treated much less than the past fifty years that led the municipality to that time (prioritizing, in this past, the trajectory of the local business and ignoring the existence of indigenous peoples and so-called "caboclos" workers) and much more from the future, using the event's coverage to publicize and propagate the lands and local economy to attract investments that would bring development to the region. We observed that in the reading of the periodical the past had to be overcome in several respects (mainly in relation to the violence practiced in a lynching) and the future, dilated, should be constantly evoked in the name of progress.
\end{abstract}

Recebido em 11 de maio de 2017. Aprovado em 21 de agosto de 2017.

\section{Introdução}

"Existe uma aceleração da História?” A pergunta feita por Reinhart Koselleck (2014) abriu um campo de discussão acerca da percepção temporal dos europeus no século XIX que vislumbravam um mundo cada vez mais acelerado: o perto e o longe, o vagaroso e o veloz, a experiência e a expectativa ganharam outros contornos e a sociedade foi capaz naquele contexto, ao contrário do passado, de voltar as atenções para o futuro. $\mathrm{O}$ progresso, a ciência e a modernidade escancarada nos trens (mobilidade mais ágil que "encurtava" distâncias), nas indústrias (a produção mais rápida de itens e a expansão do mercado), e nos demais polos da sociedade atingidos pela expansão da aceleração (política, economia, crescimento da população etc.) são indicativos, para Koselleck, da transferência de importância do espaço de experiência para o horizonte de expectativas, processo iniciado por volta do século XVI, mas consolidado apenas no XIX. O devir não dependeria mais do vivido como lição, a Historia Magistra Vitae, mas sim dos avanços tecnológicos de um mundo novo.

A aceleração é, por um lado, a transposição do tempo natural e da técnica condicionada pela natureza, para um tempo mecânico e racionalizado que resulta no encolhimento espacial.

\footnotetext{
* Mestre em História pela Universidade do Estado de Santa Catarina (Udesc). Doutorando do Programa de Pós-Graduação em História da Udesc. E-mail: gustavohst@gmail.com.
} 
Por consequência, a partir do século XVI, o encolhimento temporal também passa a ser uma questão de modernidade e não apenas religiosa (a certeza da chegada do juízo final). Para Koselleck, a aceleração histórica pode ser determinada em dois casos: 1) como abreviação do tempo das expectativas - nesse caso, a expectativa é fixada como meta e, por isso, torna-se um postulado que pode ser sempre invocado; 2) na aceleração deduzida da comparação experiencial - a velocidade da aceleração do passado versus a aceleração das mudanças no presente sendo essa aceleração subjetiva e verificável apenas no nível da experiência.

O primeiro problema a ser enfrentado nesse tema de pesquisa não é apenas o da distância territorial da Europa para o Brasil, mas sobre qual região do Brasil se pretende falar. Se na América Latina já se conheciam as estradas de ferro desde o século XIX e os processos econômicos ditos "modernos" (como o liberalismo) também já se conheciam e se praticavam (a seu modo) por aqui, é fundamental traçar importantes distinções em termos de espaço: se nós podemos falar que a experiência temporal dos centros urbanos e comerciais brasileiros é semelhante ao europeu nos seus processos de "aceleração da história", a questão fica mais complexa quando analisamos uma região brasileira que até 1917 não possuía municípios oficializados. O Oeste do estado de Santa Catarina nos coloca essa questão. A estratificação social dessa região, além de se diferenciar dos centros brasileiros, é ainda mais distinta daquela vivida pela Europa oitocentista. Indígenas de diferentes etnias, grupos ditos "miscigenados" como os "caboclos", além de paraguaios, argentinos e migrantes sul-riograndenses descendentes de italianos e alemães, compunham o quadro social dessa região por volta de 1930.

É com estas questões que buscamos nos debruçar sobre a cobertura do cinquentenário do município de Chapecón ${ }^{1}$ em 1967, pelo jornal Folha d'Oeste. Este periódico foi fundado em 1964 no município de Palmitos/SC e transferiu-se pouco depois para Chapecó. A partir do primeiro exemplar localizado ${ }^{2}$, datado de 1966, era dirigido por Homero Milton Franco (afiliado ao Partido
Social Democrático, PSD) e Gabriel Denzen. O jornal tinha circulação semanal e, no referido ano, era distribuído a 38 municípios de Santa Catarina e a uma sucursal em Guanabara (Rio de Janeiro), apresentando grande alcance para a época.

Para a análise desse periódico sob a ótica do progresso, ou seja, do horizonte de expectativas, a metodologia que nos parece mais adequada é aquela discutida por Michel Foucault e Jacques Le Goff sobre a categoria de documento/monumento. Para Le Goff (1990, p. 547-548):

O documento não é inócuo. É antes de mais nada o resultado de uma montagem, consciente ou inconsciente, da história, da época e da sociedade que o produziram, mas também das épocas sucessivas, durante as quais continuou a viver, talvez esquecido, durante as quais continuou a ser manipulado, ainda que pelo silêncio. $\mathrm{O}$ documento é uma coisa que fica, que dura, e o testemunho, o ensinamento [...] que ele traz devem ser em primeiro lugar analisados, desmistificando-lhes o seu significado aparente. $\mathrm{O}$ documento é monumento.

A metodologia empregada para analisar os periódicos aqui abordados entende que, como veículos de comunicação, os jornais lidam com representações da realidade, ou seja, têm determinada posição em relação aos acontecimentos e assumem para si o papel de "narrar" o acontecido para o presente e para o futuro, expressando no seu posicionamento parte daquele contexto específico em que atuou. Entendemos, portanto, que o "evento" coberto pelo periódico é "narrado" no sentido estrito do termo e também de acordo com os pressupostos teóricos de Koselleck.

Koselleck chama a atenção para as diversas temporalidades que atuam simultaneamente em determinado recorte temporal e/ou espacial. O "evento" e a "estrutura" provocariam uma diacronia em termos de duração, ao mesmo tempo em que esses fatores se influenciam reciprocamente (KOSELLECK, 2006, p. 133). Do ponto de vista da problemática desse estudo, a festa do cinquentenário de Chapecó permite analisar a comemoração como um "evento" local e justificado (os 50 anos 
do município), mas influenciado diretamente pela "estrutura" socioeconômica nacional e estadual de expansão do consumo e de políticas de incentivo à produção industrial levada a cabo a partir da década de 1950 até o fim do "milagre econômico" em 1973, fatores que fizeram desse "evento" um acontecimento voltado para o futuro em duas vias: na projeção de Chapecó e do Oeste catarinense para além de suas fronteiras visando à captação de recursos; e no horizonte de expectativas otimista em relação ao futuro econômico do país.

Para que possamos considerar o problema do "progresso" incluído na categoria de "horizonte de expectativas" (KOSELLECK, 2006, p. 305-327), faz-se necessário supor que também haveria "atraso e abandono" na região Oeste. Se o desenvolvimento era uma questão de ordem do dia, era porque se considerava que essa região do estado catarinense precisava de uma "redenção", que para o jornal Folha d'Oeste somente foi possível graças à instalação da Secretaria de Estado dos Negócios do Oeste (SNO) em Chapecó. A SNO (Lei no 3.283, de 17 de agosto de 1963) foi fundada pelo governador Celso Ramos (PSD) como resposta à campanha separatista de criação do estado do Iguaçu na década de 1960 (OLIVEIRA, 1998, p. 52), pretendendo integrar o Oeste catarinense na política industrial-econômica de seu governo - articulado com a Federação das Indústrias do Estado de Santa Catarina (Fiesc) para superar os impasses sociopolíticos da região, que vinha se desenvolvendo gradualmente com a agroindústria, mas sem contato efetivo com o governo catarinense, devido em grande parte à precariedade das estradas que cruzavam o estado. Embora o discurso da mídia chapecoense enfatizasse o trabalho do imigrante, o pioneirismo dos colonizadores, a "civilização" que os ítalodescendentes traziam consigo em detrimento da "vadiagem" e do "atraso" dos indígenas e dos denominados "caboclos" - discurso dominante, fundamental para a imposição do projeto almejado pelas elites locais - ainda não era possível estabelecer o Oeste catarinense como região integrada ao projeto estadual.

Três anos após a instalação da SNO em Chapecó, em 29 de janeiro, a Folha d'Oeste estampava, na capa, a seguinte frase "[...] O Oeste catarinense contiou [sic]. Sua redenção é realidade [...]" (FOLHA D'OESTE, 1966, p. 1), fazendo diversas referências ao ex-governador Celso Ramos e elencando uma série de obras de infraestrutura realizadas pela $\mathrm{SNO}$ e seu chefe, o engenheiro Serafim Enoss Bertaso (PSD/Arena), no sentido de "modernizar" o Oeste e integrá-lo no projeto político-econômico do estado de Santa Catarina. Tudo isso relacionado à pressão que o governo catarinense vinha sofrendo pelo desmembramento do Oeste para a fundação do estado do Iguaçu.

O "abandono" do governo estadual certamente não agradava uma população que desde o interior do país desejava melhorias da infraestrutura local (principalmente com relação à energia elétrica e outros serviços básicos), além de, através dessas melhorias, viver as novidades do mercado e a abundância de produtos trazidos de fora. Nesse sentido, o horizonte de expectativa do Oeste catarinense é o ingresso nos padrões de consumo que milhões de brasileiros já experimentavam desde os anos 1950, mas que não se realizava naquela região por conta da falta de energia elétrica para a maioria da população e as péssimas estradas que dificultavam a chegada de mercadorias e bens de consumo no local. Dorval Cansian, joalheiro conhecido no município, relatou para a coletânea Vida Empresarial ${ }^{3}$ como era Chapecó por volta de 1950:

Chapecó, realmente, [...], em mil novecentos e quarenta e nove, quando eu vim pra Chapecó, tinha apenas dois mil habitantes. Vejam os senhores o que Chapecó era. Não tinha construções, não tinha ruas, não tinha iluminação, a iluminação veio depois, ela tinha até às dez horas... Então era uma cidadezinha sem expressão nenhuma. (CANSIAN, 1997, p. 247).

Além de empresário do ramo de joalheria, Dorval Cansian (1997, p. 251) relata, na mesma coletânea, que tentou entrar no comércio de televisores e eletrodomésticos enfrentando problemas de infraestrutura:

O tempo foi passando, foi evoluindo e passamos a trabalhar também 
com eletrodomésticos, cinefoco e, principalmente, com televisores. Nós botamos também a seção de televisão, que na época era muito pouca gente que podia [...]. Então a gente participou da venda de rádios, eletrodomésticos e televisão. A parte da televisão é, ela, a imagem, não tava [sic] bem. Então a gente tinha problemas de vender uma televisão às vezes no interior, e não entrava a imagem de maneira nenhuma, muito ruim $[\ldots]$.

No cenário nacional, a facilidade de acesso a novos produtos por cada vez mais brasileiros provocava uma sensação de credulidade no futuro e de pronto alcance dos patamares econômicos das principais potências do mundo. De acordo com João Mello e Fernando Novais (1998, p. 560),

[...] entre 1950 e 1979, a sensação dos brasileiros, ou de grande parte dos brasileiros, era a de que faltava dar uns poucos passos para finalmente nos tornamos uma nação moderna. Esse alegre otimismo, só contrariado em alguns rápidos momentos, foi mudando a sua forma. $\mathrm{Na}$ década dos 50, alguns imaginavam até que estaríamos assistindo ao nascimento de uma nova civilização nos trópicos, que combinava a incorporação das conquistas materiais do capitalismo com a persistência dos traços de caráter que nos singularizavam como povo: a cordialidade, a criatividade, a tolerância. De 1967 em diante, a visão de progresso vai assumindo a nova forma de uma crença na modernização, isto é, de nosso acesso iminente ao "Primeiro Mundo".

Para as famílias mais abastadas do município de Chapecó, era necessário contar com caminhoneiros ou viajantes que se deslocavam frequentemente para São Paulo ou Rio de Janeiro para trazer encomendas e artigos eletrônicos, que somente começaram a se popularizar em Chapecó por volta do final dos anos 1960 e principalmente no período do chamado "milagre econômico" (19681973). Mas o futuro estava à porta. Se ainda não era através dos padrões de consumo das metrópoles brasileiras, pelo menos a industrialização do município apontava um horizonte otimista aos habitantes chapecoenses. É verdade que a política e os projetos de desenvolvimento do estado de Santa Catarina e do governo federal a partir de 1950 contribuíram decisivamente para a alteração do cenário econômico local, mas é preciso enfatizar que o frigorífico S.A. Indústria e Comércio (Saic) instalou-se em Chapecó como uma aposta das elites na mudança da matriz econômica local visando a superar a extração de madeira e como um meio de apagar ou superar o passado recente marcado por um linchamento de projeção nacional.

Percebe-se até aqui o "esquecimento" proposital de indígenas e caboclos nessa narrativa, no sentido de demonstrar que a literatura local se encarregou menos da história e da memória dessa população do que das elites. Evidentemente, esses grupos excluídos compuseram o cenário social da região vivendo isoladamente ou como fornecedores de mão de obra barata para a indústria madeireira e para os frigoríficos. Veremos, portanto, que na comemoração do cinquentenário de Chapecó pelo jornal Folha d'Oeste a seleção de quem deveria ser lembrado nos 50 anos passados privilegiou determinada camada do município, ou seja, as elites políticas e econômicas locais.

Junto ao esforço para fazer acontecer a festa do cinquentenário chapecoense, a Folha d'Oeste empenhou-se em atrair turistas através de suas páginas. Durante o ano de 1967, grande parte das edições semanais do periódico trazia o clipping "visite Chapecó", além de entrevistas com personalidades envolvidas na preparação da comemoração. Uma dessas personalidades foi o prefeito Sadi de Marco - jovem liderança do Partido Trabalhista Brasileiro (PTB) e sem partido após o Ato Institucional $\mathrm{n}^{\circ} 2$ (AI-2) -, que presidiu a Sociedade Amigos de Chapecó (SAC), órgão que se dedicou à organização e realização da $1^{\mathrm{a}}$ ExposiçãoFeira Agropecuária, Industrial e Comercial de Chapecó (Efapi). Na parte interna do jornal, em 10 de maio de 1967, multiplicavam-se pequenos artigos incentivando os leitores a convidarem parentes e amigos de fora para participarem da festa cinquentenária ou conhecerem o centro da cidade para "apreciar a beleza" dos canteiros de 
flores da avenida asfaltada: "[...] entusiasme os outros para que venham visitar Chapecó no seu maior acontecimento e divulgue essa promoção que visa à $[s i c]$ projeção de nossa cidade. Não esqueça, escreva uma carta, e fale de Chapecó" (FOLHA D’OESTE, 1967b, p. 3, grifos meus).

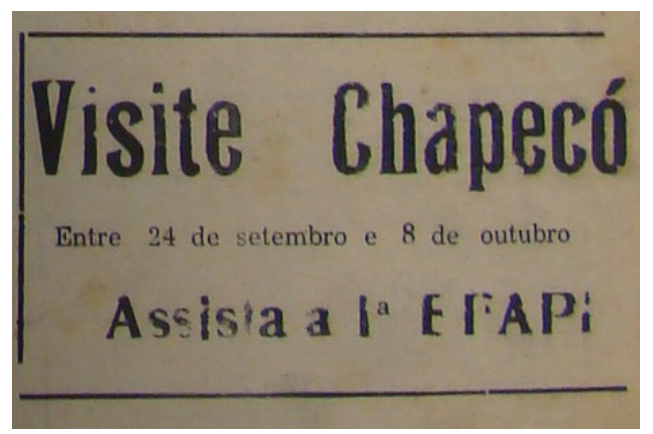

Figura 1 - Anúncio da $1^{\text {a }}$ EFAPI na capa do jornal Folha d'Oeste

Fonte: Folha d'Oeste (1967b, p. 3).

O grifo acima transparece que a comemoração dos 50 anos de Chapecó não teve apenas o intuito de rememorar o passado. Havia a intenção e a necessidade de divulgar o município para as demais regiões do Brasil, aspecto que favorecia a indústria e o comércio chapecoense. A abordagem do periódico indicava que o município, através de sua "gente batalhadora", estava sempre lutando contra adversidades; havia sempre um "apesar do trabalho intenso" ou "apesar dos esforços do empresariado local", que Chapecó enfrentava sua condição de cidade do interior brasileiro, "abandonada" ou mesmo "esquecida" pelos poderes centrais de Santa Catarina ou do Governo Federal:

Chapecoense, desprende-te de teu egocentrismo, veja a tua cidade bela e faça algo para torná-la, não somente bela, mas orgulhosa de seu povo, pela cultura, pela compreensão, pela solidariedade, de gente madura, esclarecida, porque desde o primeiro dia, Chapecó não dormia em bêrço [sic] esplêndido. (FOLHA D'OESTE, 1967b, p. 3, grifos meus).

Dessa maneira, se Chapecó persistia e crescia "apesar de tudo", era porque seu povo assim o fazia sem depender de auxílios externos, parecendo muitas vezes com um recado para municípios maiores do litoral do estado que estavam mais próximos da capital ou que tinham maior afinidade política com a situação governamental. Desde a ótica do jornal, a instalação da SNO vinha amenizando a sensação de "abandono" do Oeste, pois a presença do governo se fazia sentir por intermédio das elites políticas locais que giravam em torno da secretaria, como o engenheiro Serafim E. Bertaso. Assim, aos poucos, desenhava-se para a população chapecoense um futuro promissor tanto na ordem econômica (o crescimento da indústria local e o acesso a novos bens de consumo) quanto na ordem política (o estado de Santa Catarina parecia finalmente oferecer esforços para a "redenção do Oeste"), expectativas estas devidamente canalizadas pela Folha d'Oeste.

Quanto mais próximo da data da primeira Efapi, mais crescia a expectativa do jornal. Vai se delineando claramente que a intenção maior era realizar um evento voltado para o futuro e não para o passado. Faltando quatro meses para a festa, em 31 de maio de 1967, o periódico destacou:

Indústrias de renome no Brasil estarão expondo seus produtos em nossos "stands" e seus representantes, ao vir a Chapecó, irão sentir quão grandiosa é a região oestina. Sentirão quanto importante é investir capital em indústrias básicas nesta região.

Saberão, os homens de negócios, que no Oeste situam-se as terras mais férteis do Mundo (segundo pesquiza $[s i c]$ da FAO). Serão informados, êsses [sic] homens de que o Oeste Catarinense, "per capita" é o maior celeiro agrícola do Brasil. Ficarão sabendo que em Chapecó constroem-se, em média 15 casas de moradia por mês e 12 edifícios de mais de dois andares por ano.

Conhecerão, todos que aqui vierem, a grandiosidade do povo oestino, por seu trabalho por sua luta, pela sua dignidade, pela sua vontade de crescer. (FOLHA D’OESTE, 1967d, p. 3, grifos meus).

Ospreparativosparaafestadocinquentenário revelam que o grande imperativo do evento era a divulgação de Chapecó e do Oeste catarinense para o país com o intuito de atrair investidores (e capital) 
para a economia local e como um lugar onde vivia um "povo grandioso", "trabalhador" e "digno" (e, consequentemente, não violento como aquele povo que protagonizara um linchamento). Cabe ressaltar que até aquele momento o município de Chapecó ainda se dedicava a crescer e ser reconhecido como uma potência produtiva no estado; por isso, a propaganda dos recursos naturais ("as terras mais férteis do mundo") e de sua população com "vontade de crescer" era fundamental para o evento.

As pessoas que compunham esse grande organismo empenhado em fazer a festa de comemoração na cidade retratam o próprio resultado dessa rememoração. Líderes políticos e grandes empresários estavam envolvidos de forma pessoal ou coletiva. No coletivo, destacamse os clubes de serviço e associações de classe que auxiliavam na organização do evento. Como procuramos demonstrar na dissertação de mestrado intitulada Os donos do "Celeiro do Progresso": redes sociais e política (Chapecó, 1956-1977) (SIQUEIRA, 2016), as elites políticas e econômicas locais possuíam vínculos que iam além das relações institucionais, pois essas pessoas compartilhavam dos mesmos espaços de socialização (clubes e associações), onde o capital social era incrementado e, em alguns casos, convertido em capital político que visava à manutenção do poder. Esses espaços, cada um a seu modo, afirmavam os valores que transparecem na narrativa da festa cinquentenária, ou seja, o "trabalho", o "progresso", o "pioneirismo" e etc. Em entrevista para a Folha d'Oeste, um dos organizadores da festa, Valmor Lunardi (Arena), afirmou que: "convidou-se tôda [sic] a população para que tomasse parte nesta organização que se denomina Sociedade Amigos de Chapecó - SAC - congregando elementos de clubes de serviço, autoridades e representantes classistas" (FOLHA D’OESTE, 1967c, p. 1), ou seja, a "população" não participava diretamente da elaboração, mas era representada pelas organizações comandadas pelas elites locais - os clubes de serviço e representantes classistas -, como a Associação Comercial e Industrial de Chapecó (Acic), o Rotary Clube e o Lions Clube de Chapecó.

Apesar da carência de infraestrutura e melhores condições materiais da população chapecoense naquele momento, o investimento na festividade foi alto. A SNO, por meio do secretário Serafim E. Bertaso, destinou uma verba de 100 milhões de cruzeiros do orçamento da pasta para a construção de pavilhões para a exposição e a Câmara Municipal de Chapecó e o prefeito Sadi de Marco aprovaram o valor de 20 milhões para o evento. Com esses valores, além da impressão de material gráfico para a divulgação da festa do cinquentenário, Valmor Lunardi afirmou que "[...] tem-se contratado com duas firmas cinematográficas a execução de quatro filmes documentários, dos quais dois já foram filmados e estão rodando nos circuitos do Rio Grande do Sul, Santa Catarina e Paraná" (FOLHA D’OESTE, 1967c, p. 1), mostrando que, apesar de pouca gente ter acesso aos bens de consumo audiovisuais (com a aquisição de televisores ou ir com frequência ao cinema local), a prefeitura e o próprio jornal (com sua respectiva organização de classe, a Associação Oestina de Imprensa e Radiodifusão, AIRA) esforçaram-se para organizar um evento "moderno" que se destacasse dentro e fora do estado catarinense.

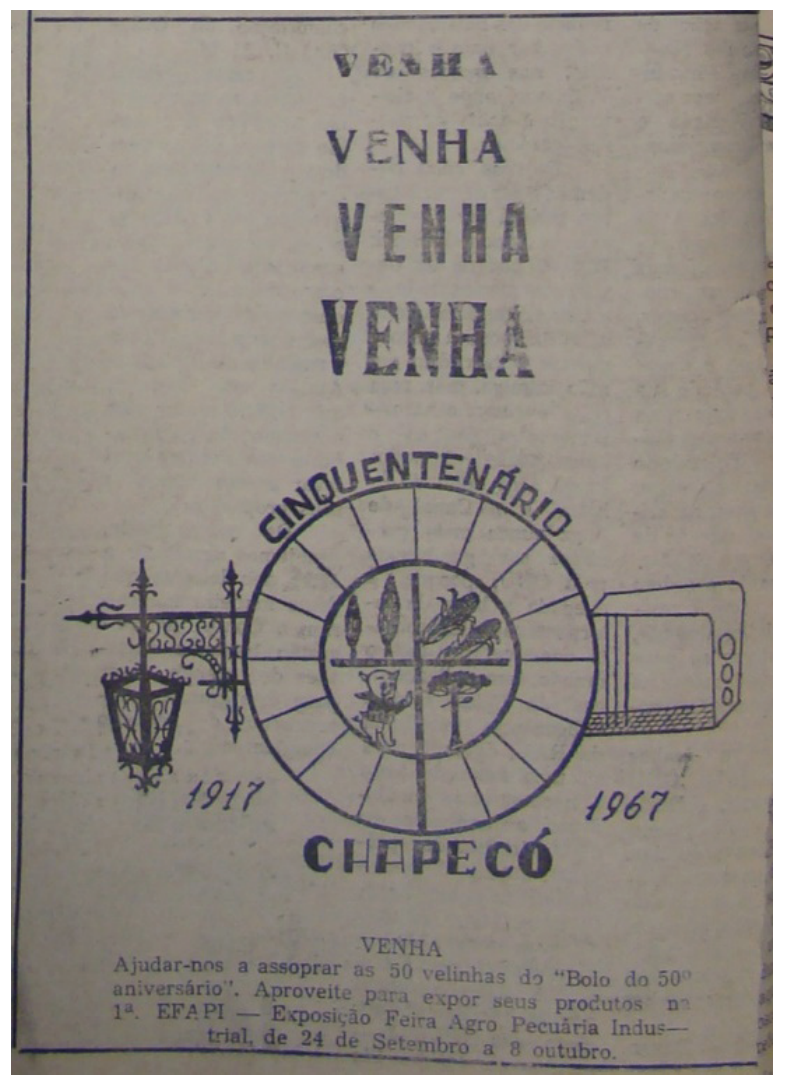

Figura 2 - Anúncio da $1^{\text {a }}$ EFAPI no jornal Folha d'Oeste Fonte: Folha d'Oeste (1967f, p. 4). 
O projeto das elites locais passava por uma mudança visual do município. De um lado, pela iniciativa da prefeitura na realização de obras de ornamentação no centro da cidade, como a colocação de canteiros de flores, instalação de bancos na avenida e de um chafariz de luzes na praça, objetivando "mais beleza, mais confôrto [sic] [e] mais requinte", conforme citado na edição ${ }^{\circ}$ 100 do jornal, (FOLHA D’OESTE, 1967b, p. 3); e, de outro, pela eleição da "Rainha do Cinquentenário", competição que foi realizada na ocasião da primeira Efapi, e para a qual, em 10 de junho de 1967, o colunista da Folha d'Oeste, Ivanor Vanzin, na capa da edição n. 103, prometera em favor da candidata da AIRA uma "[...] batalha de rosas que estará voltada para o enaltecimento da terra de Condá e o maior prestígio da Capital da Simpatia" (FOLHA D’OESTE, 1967e, p. 1). Aquela Chapecó descrita anos antes na revista Cruzeiro como um cenário de farwest habitado por bandidos (linchadores) passou 17 anos depois por uma reformulação visual de sua principal avenida e pela divulgação de ações cívicas - como o concurso de beleza das mulheres e outras atrações - visando a divulgar outra imagem de sua população. Além disso, a Folha d'Oeste trazia em suas reportagens diversos exemplos de moradores que pintaram a fachada de suas casas e comércios da região central para receber os turistas.

Faltando uma semana para o início da Efapi, a Folha d'Oeste expressou a ansiedade pelo evento na edição $n^{\circ} 112$, em 12 de agosto de 1967. Com exceção de poucas iniciativas em favor do resgate histórico dos 50 anos de Chapecó - como uma exposição fotográfica realizada pelo Lions Clube -, a tônica geral da festividade era a promoção do município e do Oeste catarinense para o resto do país:

Dos efeitos benéficos desta promoção não se pode falar ainda, mas, sabese, muito progresso, mais inversão de dinheiros públicos e privados, maior conhecimento sôbre [sic] as possibilidades de desenvolvimento da região, além de simpatias e relações humanas e públicas, teremos feito, visando um futuro brilhante $e$ promissor para nossa cidade e região. (FOLHA D’OESTE, 1967g, p. 3, grifos meus).
A narrativa do jornal torna evidente que a expectativa do futuro era mais importante do que a experiência do passado. Dessa maneira, interessava menos ao periódico e seus editores o processo histórico que levara Chapecó até onde se encontrava e dava-se maior importância para aquilo que o município poderia ser no futuro.

$\mathrm{Na}$ "edição especial do cinquentenário de Chapecó", único exemplar pesquisado a trazer cores na capa, a Folha d'Oeste publicou um texto em forma de declaração de amor para a cidade em 24 de setembro de 1967. Nele, destacam-se as presenças e as ausências. Presença do nome dos colonizadores Manoel de Passos Maia, Ernesto Bertaso e José Bernardino Bormann; presença do "branco europeu" que "derrubou árvores e cultivou as terras"; presença e homenagem à Igreja e à Secretaria dos Negócios do Oeste; presença do riacho do centro da cidade, canalizado em favor do "asfalto negro do progresso"; presença do migrante sul-riograndense; presença do Clube Recreativo Chapecoense, "o mais lindo clube social do Estado", além da alusão a Chapecó como "uma garôta [sic] dos olhos azuis, cabelos negros, ondeados e que enamoras os [...] pretendentes", segundo a Folha d'Oeste (1967h, p. 1). As ausências sentidas se referem às populações indígenas - com exceção de uma breve menção ao controverso índio Condá - e também das populações caboclas, grupos submetidos ao esquecimento na narrativa no periódico.

Esta edição especial, de 33 páginas, apresenta os mais diversos fatores que, do ponto de vista do periódico, valiam a pena recordar como elementos engrandecedores do município. O que se percebe, no entanto, é que poucas dessas páginas dedicaramse à história local: uma matéria intitulada "Como nasce um município gigante", abordando as ações de bandeirantes paulistas e a colonização do município; uma cronologia do Oeste catarinense e uma matéria intitulada "Hegemonia de Chapecó", sobre as transformações territoriais da região, foram as únicas menções a esta temática.

As demais páginas da edição especial são dedicadas quase exclusivamente às "empresas pioneiras" do município, como as das famílias 
De Marco (no ramo de automóveis e vestuário), Sperandio (automóveis), Silvestri (vestuário), Damo (vestuário e advogados), Tozzo (indústria) e outros, além de personalidades locais como Arnaldo Mendes (colonizador e membro da Arena), Plínio Arlindo de Nês (diretor da Saic e membro da Arena) e Serafim Bertaso (secretário do Oeste, também da Arena) e seu pai, Ernesto Bertaso. Tiveram espaço também as ações governamentais (tanto do executivo e legislativo municipal quanto do judiciário estadual) e pequenos textos exaltando a qualidade da terra e o potencial produtivo do Oeste catarinense, além de dezenas de publicidades.

Em edições seguintes, como a $\mathrm{n}^{\circ} 119$, o jornal conclui que "Chapecó progrediu 20 anos em menos de seis meses" e que outras feiras catarinenses "não tiveram têrmo [sic] de comparação em número de visitantes" (FOLHA D’OESTE, 1967i, p. 6). Em dezembro de 1967, a Folha d'Oeste trazia na capa uma matéria na qual afirmava que o crescimento de Chapecó superava a da metrópole São Paulo, de acordo com pesquisas "técnicas" do setor de água e esgoto do município. Em 2 de dezembro de 1967, o jornal menciona que, com uma taxa de crescimento de $12,5 \%$ ao ano, os técnicos estimavam que:

[...] Chapecó terá, obrigatoriamente, 300.000 habitantes, desde que continue essa inflação desordenada na sua explosão demográfica, parte com recursos próprios de proliferação humana e a maioria por pessoas de todos os quadrantes do Brasil que para cá se deslocam à procura de melhores oportunidades na vida, nos negócios e na indústria. (FOLHA D’OESTE, 1967k, p. 1).

Evidencia-se, portanto, a expectativa de futuro grandioso no setor produtivo, amplamente propagandeado no jornal, que geraria a "maioria" de pessoas responsáveis por essa explosão demográfica de Chapecó. Esse montante de 300 mil pessoas, prognosticado para 1990, não foi atingido até o momento, em 2017. É outro indício, contudo, de que o horizonte de expectativa contido na narrativa do jornal estava dilatado em detrimento do espaço de experiência.
$\mathrm{Na}$ pesquisa empreendida nesse artigo, priorizou-se a cobertura dos preparativos e do evento para a primeira Efapi de Chapecó, inserida nas comemorações do cinquentenário local. Todavia, folheando o jornal, chamou a atenção um fato ocorrido em São Miguel d'Oeste que ajuda na reflexão desse estudo. Um delegado de polícia daquele município, o militar Dino Corte, teria levado um suspeito até a delegacia e sem qualquer motivo aparente começou a espancá-lo. Ao sair do local, a vítima denunciou o ocorrido a conhecidos e estes formaram uma multidão de centenas de pessoas para atacar o agressor. Quando estava prestes a ser linchado, já apresentando algumas escoriações, o delegado foi salvo pela intervenção do juiz de direito do local, Carlos Nosse. O delegado teria sido preso e solto pouco depois mediante pagamento de quatro cruzeiros.

Seria uma reportagem comum sobre abuso de autoridade, se o ocorrido não fosse tratado pelo jornal, em 14 de outubro de 1967, como "o fato policial de maior vexame nos últimos tempos em Santa Catarina” (FOLHA D'OESTE, 1967h, p. 6); e, algumas edições mais tarde, especificamente a $\mathrm{n}^{\circ} 122$, de 11 novembro de 1967, trata a multa paga pelo delegado como a "maior piada oestina dos últimos 50 anos" (FOLHA D’OESTE, 1967j). Acontece que a própria população de Chapecó provocara um linchamento (e não uma tentativa) 17 anos antes, em 16 de outubro de 1950 (HASS, 2007). Romano Ruani, Ivo Oliveira Paim e os irmãos Orlando e Armando Lima foram presos, acusados de incendiar a Igreja Católica local para furtar residências circundantes, prática comum entre bandidos da época. Parte da população, indignada com o incêndio da construção, erguida pela comunidade, organizou-se após a notícia de que os supostos incendiários seriam transferidos da cadeia municipal de Chapecó para Joaçaba, devido à tensão que se instalava em torno do caso. Inconformadas com a "falta de justiça", cerca de 200 pessoas se organizaram e lincharam os presos. $\mathrm{O}$ então delegado de polícia de Chapecó e responsável pela prisão dos "incendiários" da Igreja, Arthur Argeu Lajus, não ofereceu qualquer proteção aos presos. Era pessedista, balseiro e grileiro de terras, 
além de ser conhecido entre a população pelo abuso de autoridade e por ser mandante de torturas e assassinatos. Para agravar a situação dos presos, os irmãos Lima eram petebistas, ou seja, oposicionistas do partido do delegado.

Por isso nos causa estranhamento a cobertura do "princípio de linchamento" de São Miguel d'Oeste como o "maior vexame" a relativamente pouco tempo da barbaridade cometida por moradores de Chapecó. Este estranhamento, contudo, se desfaz se considerarmos a perspectiva desse artigo, ou seja, de que o passado chapecoense foi encurtado em favor da dilatação do futuro. Era fundamental superar aquele passado ligado ao banditismo, e a superação desse passado poderia ser realizada colocando outro fato grave em relevância, sendo "o mais vexatório", no qual a punição pelo crime fora "uma piada". Não importava, aparentemente, que os linchadores de Chapecó e mesmo o delegado Lajus não tenham sido devidamente punidos - e que a disputa política fora a tônica desse processo (HASS, 2007) -, visto que o periódico sequer mencionou o caso chapecoense a título de exemplo recente e marcou o caso de São Miguel d'Oeste ao abordá-lo em outras edições ao longo do resto do ano.

\section{Considerações finais}

Percebemos, na análise empreendida aqui, que a narrativa do jornal Folha d'Oeste apresenta um regime de historicidade representado pela aceleração da história e a dilatação do horizonte de expectativas. Koselleck aponta que a aceleração deriva da abreviação do tempo das expectativas e estas expectativas são fixadas como metas que podem ser sempre invocadas, ou seja, o jornal descrevia Chapecó e a região Oeste catarinense como um lugar promissor (de terras produtivas, de pessoas trabalhadoras; enfim, como possuidora de todos os elementos necessários para captação de investimentos e recursos financeiros), transparecendo a intenção de promover a cidade para o futuro e invocando constantemente o objetivo do "progresso". Enquanto nas metrópoles brasileiras vivia-se a modernização trazida pelas novas indústrias e pela expansão da oferta de bens de consumo, a cidade de Chapecó parecia "atrasada". A superação desse "atraso" passava pelas festividades do cinquentenário, daí o forte apoio do periódico ao evento. A editoria do jornal referia-se ao presente como um "quase lá", apontando para o futuro, como quem busca "acelerar" a história local rumo ao progresso.

Como apontado no texto, o passado teve pouco espaço nas edições da Folha d'Oeste referentes à comemoração do cinquentenário. Com exceção de pequenos textos na edição especial, predominaram naquelas páginas a trajetória do empresariado local, o balanço das finanças da indústria, publicidades variadas e o enaltecimento das obras do prefeito Sadi de Marco e da Secretaria dos Negócios do Oeste, além da propaganda direcionada à captação de recursos. O espaço de experiência, encolhido, é reservado ao comércio e às elites política e econômica de Chapecó, impondo um silêncio em torno das populações caboclas e indígenas. $\mathrm{O}$ horizonte de expectativa, dilatado, prognosticava um futuro de progresso e prosperidade para o município. Essa perspectiva histórica, como vimos, colocava-se em conformidade com a "estrutura" socioeconômica nacional.

O contexto discutido nesse artigo - e suas conclusões no que se refere à aceleração da história e o horizonte de expectativas dilatado - é o "pano de fundo" que ilustra a perspectiva histórica que durou pelo menos até meados da década de 1970. Apesar de o complexo agroindustrial continuar crescendo muito nesse período, começava a ficar claro aos mais pobres que a narrativa do "progresso" não funcionava para todos. Segundo Mello e Novais (1998, p. 560), se entre as décadas de 1950 e 1970 viveu-se uma euforia de crescimento do país, a partir dos anos 1980, "[...] entretanto, assiste-se ao reverso da medalha: as dúvidas quanto às possiblidades de construir uma sociedade efetivamente moderna tendem a crescer e o pessimismo ganha, pouco a pouco, intensidade". É nessa conjuntura que se desenvolve a Teologia da Libertação na América Latina e o bispo de Chapecó, Dom José Gomes, já ordenava as primeiras Comunidades Eclesiais de Base na região Oeste de Santa Catarina, expandindo o horizonte político da região. 


\section{Notas}

1 Localizado a aproximadamente 550 quilômetros da capital Florianópolis, o município de Chapecó foi fundado em 25 de agosto de 1917, após resolução do impasse interestadual entre Santa Catarina e Paraná na Guerra do Contestado (1912-1916). Seu território abrangia todo o Oeste catarinense e foi desmembrandose em novos municípios ao longo do século até a década de 1990.

2 A pesquisa do jornal Folha d'Oeste foi realizada no arquivo do Centro de Memória do Oeste de Santa Catarina (Ceom), em Chapecó, durante o ano de 2015.

3 Série editada pela Associação Comercial e Industrial de Chapecó (ACIC) e publicada pelo curso de Administração da Universidade do Oeste Catarinense (UNOESC), que consiste em transcrições de palestras de empresários locais sobre suas trajetórias profissionais.

4 Um fator relevante a respeito dessa eleição é que as candidatas, em sua totalidade, foram indicadas e apoiadas pelos clubes de serviço e associações de classe locais.

$5 \mathrm{Na}$ narrativa oficial, o Kaingang Victorino Condá teria sido um pacificador que lutou por terras em favor dos indígenas. Contudo, para os próprios Kaingangs que vivem atualmente em Chapecó, Condá foi um aliado dos bandeirantes paulistas que preteriu os interesses de seu povo em favor dos colonizadores brancos.

\section{Referências}

ASSOCIAÇÃO Comercial e Industrial de Chapecó. Vida Empresarial. Vol. 2. Chapecó: Grifos, 1997.

\section{HASS, M. O linchamento que muitos querem} esquecer: Chapecó, 1950-1956. 2. ed. Chapecó: Argos, 2007.

JORNAL FOLHA D’OESTE. Chapecó, n. 59, 29 jan. 1966, p. 1.

Chapecó, n. 100, 10 maio 1967b, p. 3.

Chapecó, n. 101, 20 maio 1967c, p. 1.

Chapecó, n. 102, 31 maio 1967d, p. 3.
. Chapecó, n. 103, 10 jun. 1967e, p. 1.

Chapecó, n. 104, 17 jun. 1967f, p. 4.

Chapecó, n. 112, 12 ago. 1967g, p. 3.

Chapecó, ed. especial, 24 set. 1967h, p. 1.

Chapecó, n. 119, 14 out. 1967i, p. 6

Chapecó, n. 122, 11 nov. 1967j, p. 1.

. Chapecó, n. 126, 2 dez. 1967k, p. 1.

KOSELLECK, R. Estratos do tempo: estudos sobre a História. Rio de Janeiro: Contraponto; Ed. PUCRJ, 2014.

Futuro Passado: Contribuição à semântica dos tempos históricos. Rio de Janeiro: Contraponto; Ed. PUC-Rio, 2006.

LE GOFF, J. História e Memória. Campinas: Editora da UNICAMP, 1990.

MELLO, J. M. C.; NOVAIS, F. Capitalismo Tardio e Sociabilidade Moderna. In: SCHWARCZ, L. M. (Org.). História da vida privada no Brasil: contrastes da intimidade contemporânea. São Paulo: Companhia das Letras, 1998, p. 559-658.

OLIVEIRA, L. "Estado do Iguaçu”: o regionalismo em questão. 1998. 163 f. Dissertação (Mestrado em Ciência Política) - Programa de Pós-Graduação em Ciência Política, Universidade Estadual de Campinas, Campinas, 1998.

SIQUEIRA, G. Os donos do "Celeiro do Progresso": redes sociais e política (Chapecó, 1956-1977). 2016. 155 f. Dissertação (Mestrado em História) - Programa de Pós-Graduação em História, Universidade do Estado de Santa Catarina, Florianópolis, 2016. 